www.jmscr.igmpublication.org

Index Copernicus Value: 79.54

ISSN (e)-2347-176x ISSN (p) 2455-0450

crossrefDOI: https://dx.doi.org/10.18535/jmscr/v7i2.183

\title{
Study of single dose methotrexate for medical treatment of ectopic pregnancy
}

\author{
Authors \\ Neena Agrawal $^{1^{*}}$, Pallavi Kumari ${ }^{2}$ \\ ${ }^{1}$ M.D. (Obst. \& Gynae.), Assistant Professor, Department of Obstetrics \& Gynaecology, \\ Nalanda Medical College \& Hospital, Patna, Bihar \\ ${ }^{2} 2^{\text {nd }}$ year PG student, In Obst. \& Gynae \\ *Corresponding Author \\ Neena Agrawal, M.D. (Obst. \& Gynae.) \\ Assistant Professor, Department of Obstetrics \& Gynaecology, Nalanda Medical College \& Hospital, Patna, \\ Bihar, India
}

\section{Introduction}

Ectopic pregnancy occurs when fertilize ovum implants outside the uterine cavity. Incidence is 0.5 per hundred pregnancies. Previously the treatment of ectopic pregnancy was limited to surgery. With the advent of methotrexate the treatment of selected cases of an ectopic pregnancy is viable alternative to surgical treatment. Methotrexate is an anti-metabolite that interferes with DNA synthesis and disrupts cell proliferation. Medical therapy has advantage over surgical therapy for number of reasons including eliminating morbidity from surgery and General Anesthesia, potentially less tubal damage and less cost. Successful medical treatment with methotrexate can help preserve the chance for future healthy pregnancies.

\section{Materials \& Methods}

All the patients diagnosed with ectopic pregnancy during the period of two years (July 2016 to June 2018) where including in the study group in the department of obstetrics and gynecology, Nalanda Medical College Hospital in Patna. Total 38 patients were included with selection criteria of -

1. Hemodynamically stable patients.

2. Serum beta hCG levels less than 5000 IU/L.

3. Adnexal mass of less than $4 \mathrm{~cm}$.

4. Less than $300 \mathrm{ml}$ of free fluid in Pouch of Douglas.

5. Patient in whom methotrexate is not contraindicated.

The dose of methotrexate in these patients were calculated as $1 \mathrm{mg} / \mathrm{kg}$ body weight. Given intramuscular the patient. The patients were observed for abdominal pain \& any signs and symptoms of rupture.

The patient were warned that the therapy might fail in 5 to $10 \%$. Folic acid was avoided.

Transvaginal sonography and serum beta hCG level were performed on Day $4 \&$ Day 7 of the Injection methotrexate. If serum beta hCG level decreased greater than $15 \%$ of initial level and if 
there were no signs of rupture, patients were then followed up with weekly serum beta hCG level as outpatient, till the time it reached to the non pregnant level. If serum beta hCG level increased or decreased less than $15 \%$ of the intial level on day 7 , second dose of injection methotrexate was given. Treatment was described as successful if no surgical intervention was needed. Surgical intervention was done for tubal rupture or tubal abortion.

\section{Results}

Total of 26 out of 42 cases were successfully treated with single dose of injection methotrexate $\& 8$ out of $42(19 \%)$ required additional dose of injection methotrexate. Total 34 cases out of 42 successfully treated and 8 cases underwent surgery due to tubal abortion and rupture.

\section{Discussion}

Are finding suggest that single dose methotrexate as a success rate of $62 \%$ medical treatment of an ectopic pregnancy with methotrexate is safe and effective in carefully selected cases. In the study by clara Merisio etr al on 11 patients success rate with single dose of MTX was higher (90\%) and similar to ours study lower $\square$-hCG level had significantly relation with success of treatment 10 . In the study carried out by MM Alshimiri on 77 cases success rate was $95 \%$ (73 patients) and this is comparable to our srudy.

Amelie Gervaise et al also reported success rate $65.1 \% 41$ out of 63 patients) $19 \%$ of patients (12 patients) required to second dose of MTX and 8 out of these 12 patients $(12.6 \%)$ underwent emergency laparotomy and this is comparable to ours studies.

This also that medical treatment of EP with MTX is safe and effective in carefully selected cases. Methotrexate treatment is beneficial to avoid surgery in a patient but it requires extended follow-up of patients which can be cumbersome and difficult for some patients.

\section{Conclusion}

In conclusion this hospital based study of medical treatment of an ectopic pregnancy with systemic methotrexate in $\mathrm{NMCH}$ is comparable to other part of the world. Although methotrexate treatment is beneficial in that it allows one to avoid surgery in a patient, there are certain disadvantages like long follow up. Whereas surgical management is safe effective and requires less visits. Further more patients who are treated surgically have same fertility as those treated with NTX. So in conclusion medical therapy although and accepted option requires early diagnosis proper selection criteria. The choice between two acceptable treatments, medicine or surgery, should be an informed, not reflective decision.

\section{References}

1. Medical management of ectopic pregnancy, ACOG Practice Bulletin \#94. American College of Obstetricians and Gynecologists. Obstet Gyecol 2008 Jun; 111(6):

2. Stovall TG, Ling FW, Buster JE. Outpatienht chemotherapy of unruptured ectopic pregnancy. Fertil Steril. 1989; 51:435-8. [PubMed].

3. Lipscomb GH. Medical treatment of ectopic Pregnancy, Clin Obstet Gynectol 2012 Jun; 55(2) : 424-32.

4. Cunnibngham FG, et al. Ectopic pregnancy. In Williams Obstetrics, $23^{\text {rd }}$ ed., New York: McGraw-Hill, 2010 pp: 238-256.

5. American College of Obstetricians and Gynecologists (2008, reaffirjed 2012). Medical management of ectopic pregnancy. ACOG Practice Bulletijn No. 94. Obstetrics and Gynecology, 111(6) : 1479-85. 